\title{
The fate of a Military Pilot in Malaysia: Lingering on the ground after young stroke
}

\author{
Mohammad $Z^{1,2}$, Ibrahim AA ${ }^{1}$, Ismail $\mathbf{R}^{1}$, Abdul Manaf MR $^{1}$ \\ ${ }^{1}$ Department of Community Health, Faculty of Medicine, Universiti Kebangsaan Malaysia Medical Centre, \\ Malaysia. \\ ${ }^{2}$ Institute of Aviation Medicine, Subang Air Base, 40000 Shah Alam, Selangor, Malaysia.
}

\section{ABSTRACT}

Strokes in young pilots can result in the devastating loss of productive years of life, especially for pilots at the peak of their careers. A 32-yr-old male military helicopter pilot was diagnosed with superior sagittal sinus thrombosis and bilateral parietal hemorrhages secondary to protein $S$ deficiency after 15 years in military service. Two years post-stroke, he was carefully evaluated for a possible return to work after aeromedical assessment and the 1 percent rule being considered. A decision was made by the medical board for him to be disqualified to fly and grounded with work accommodation. The authors recommend that there is a need for reassessment up to two years using the objective PULHEEMS method for young pilots who failed aeromedical assessment due to stroke for returning to work as their experiences and knowledge is highly valuable.

Key words: Aircraft, Malaysia, Return to work, Stroke, Workplace

\section{INTRODUCTION}

S trokes in young pilots can result in the devastating loss of productive years of life, especially for pilots at the peak of their careers. Most experts consider the age of young stroke patients to be under 45 years old. However, some studies may define a young stroke patient as one who suffers a stroke before the age of 65. ${ }^{1}$ Globally, $10 \%$ of living stroke survivors are under the age of $44 .^{2}$ In a developed country, the incidence of stroke doubles with each decade after the age 45 years. ${ }^{3}$

DOI: https://doi.org/10.3126/ijosh.v12i1.41038

Conflicts of interest: None

Supporting agencies: None

Date of submission: 03.06.2021

Date of acceptance: 20.09.2021

Date of publication: 01.01.2022

\section{Corresponding Author}

Rosnah Ismail

Department of Community Health,

Faculty of Medicine, Universiti Kebangsaan Malaysia Medical Centre,

Jalan Yaacob Latiff, 56000 Cheras, Wilayah Persekutuan Kuala Lumpur,

Malaysia.

Email: drrose@ppukm.ukm.edu.my

ORCID: https://orcid.org/0000-0002-8178-3822
The incidence of stroke increase with age, primarily due to atherosclerosis. Atherosclerosis is associated with several risk factors: high blood pressure (57.3\%), poor diet $(51.1 \%)$, high body mass index $(23.6 \%)$, smoking (23.4\%), high fasting glucose (17.3\%), and alcohol use $(11.9 \%) .{ }^{2}$ For military pilots in the Royal Malaysia Air Force (RMAF), those risk factors are minimized and monitored yearly. Each pilot undergoes an aeromedical assessment which includes biochemical blood tests. Physically, pilots are assessed under the Armed Forces Medical Classification System (AFMeCS) which is labeled as PULHEEMS and represent a measurement of physical capacity $(P)$, upper limbs $(U)$, locomotion $(L)$, hearing acuity $(H)$, both eyesight $(E E)$, mental capacity (M) and stability (S), to ensure they fit for flying. ${ }^{4}$ All qualities are graded from one to eight, with one being excellent and eight being unfit for service, as shown in Table 1. The minimum requirements for a military pilot are assessments of degree 2 (normal) for each quality except for $\mathrm{H}$ and $\mathrm{EE}$, which must be degree 1.

This journal is licensed under a Creative Commons AttributionNon Commercial 4.0 International License.
} 
Table 1: Permissible Grade of Degree for Each Quality

\begin{tabular}{ccccccc}
\hline $\mathbf{P}$ & $\mathbf{U}$ & $\mathbf{L}$ & $\mathbf{H}$ (high/low frequency levels in dB) & $\mathbf{E E}($ Snellen Chart) & $\mathbf{M}$ & $\mathbf{S}$ \\
\hline & & & $1(\leq 60 / \leq 45)$ & $1(6 / 6)$ & & \\
2 & 2 & 2 & $2(\leq 112 / \leq 123)$ & $2(6 / 9)$ & 2 & 2 \\
3 & 3 & 3 & $3(\leq 200 / \leq 210)$ & $3(6 / 12)$ & 3 & 3 \\
& & & & $4(6 / 18)$ & & \\
& & & & $5(6 / 24)$ & & \\
7 & 7 & 7 & $7(>200 />210)$ & $7(6 / 60)$ & 7 & 7 \\
8 & 8 & 8 & $8(>360 />270)$ & $8(<6 / 60)$ & 8 & 8 \\
0 & 0 & 0 & & & & \\
\hline
\end{tabular}

For the quality of $\mathrm{P}, \mathrm{U}$ and $\mathrm{L}$, it will be assessed under degrees $0,2,3,7$, and 8 . The degree of 0 for those who are under medical care and remain unfit for duty for a certain period. If it becomes apparent that the patient is unlikely to return to work due to medical reasons, he will be assessed at degree 8 , and discharge to the medical board is to be considered. The quality of physical capacity $(P)$ indicates an individual's overall physical and mental capacity. Any pathological condition in other qualities will affect the $\mathrm{P}$ grading. In some diseases such as stroke, it is specifically spelled out in the guideline that if the patient remains independent for activities of daily living, downgrade to $\mathrm{P} 3$ or P7.

For assessment of upper limb (U), functional use of the hands, arms, shoulder girdle, and upper spine will be examined. Here, the term function is used to indicate the capacity to perform activities with the upper limb. As a military officer, at a minimum, be able to handle weapons and carry weights. Locomotion (L) assesses the functional efficiency of the locomotor system from the lower spine to the feet and includes observation of gait and mobility. Normal findings will be graded as degree 2. However, any impairment will be downgraded to degree 3 and any hindrance of operational deployment due to the severity of cases will be further degraded to degree 7 .

As for the quality of hearing acuity $(H)$, audiometric tests will be done by summing of high-frequency levels $(0.5,1,2,3 \mathrm{kHz})$ and low-frequency levels $(4,6,8 \mathrm{kHz})$ in decibels $(\mathrm{dB})$. There are five degrees of hearing acuity: 1, 2, 3, 7, and 8. On the other hand, an accurate assessment of both eyesight (EE) is using Snellen's Test chart. The assessment of mental capacity (M) indicates the officer's ability to learn and carry out tasks. It is made by careful history-taking with special reference to previous work records, basic cognitive tests such as Mini-Mental State Examination (MMSE), and the impression given on personal interview about alertness and the ability to apply usefully intelligence. The quality of stability (S) is about his emotional stability which includes temperament and ability to withstand the stress and pressure of a job or duties given to him. This quality is affected principally by psychiatric disorders such as anxiety disorder or depressive illness. Any signs of intellectual, emotional, or character disorder and symptoms of psychosomatic disorder should be referred to the military psychiatrist. Any alteration of the degree can only be determined by military psychiatrists.

Generally, a status of fit-to-fly for pilots means they do not have underlying medical conditions that result in a risk of medical incapacitation greater than $1 \%$ per annum. ${ }^{5}$ This 1 percent rule, also known as maximum level incapacitation risk, has been used internationally by the United Kingdom Civil Aviation Authority (CAA), United State Air Force (USAF), European Union Aviation Safety Agency (EASA) and Federal Aviation Administration (FAA) as a fundamental threshold in aeromedical assessment. A previous study found the annual incapacitation rate among pilots was $0.25 \%$. It was recorded that $90 \%$ of events presented as incapacitations were due to non-communicable diseases and $11.1 \%$ were due to stroke events. ${ }^{6}$ Having a stroke among pilots may pose risk both to the public safety as well as national securities.

As a consequence, those pilots with medical incapacitation rate of $1 \%$ and above are disqualified to fly and are grounded, a decision based on the medical board's assessment of the risk of a pilot returning to work. There are numerous ways to do a return-towork assessment for pilots. For example, a risk matrix is often generated by combining the probability and consequences of medical events to determine a pilot's fitness to fly. ${ }^{7}$ However, return-to-work assessments conducted by the Malaysian military rely on the 
PULHEEMS system, which provides distinct value after medical incapacitation. Thus, this case report is aimed at providing further understanding of aeromedical assessment and guidance for relevant authorities.

\section{CASE DESCRIPTION}

This case study outlines the occupational health care of a military helicopter pilot who suffered a stroke at a young age. The patient was a 32-year-old man when he was diagnosed with superior sagittal sinus thrombosis (SSST) and bilateral parietal hemorrhages secondary to protein $\mathrm{S}$ deficiency.

The catastrophic event started after 15 years of military service with no assessed risk of medical incapacitation. Initially, he was admitted to the hospital for further investigation after having a prolonged headache and fever. Provisionally, he was treated for meningitis by the physician in charge. However, after almost a week in the ward, he experienced a sudden onset of righthand weakness followed by three episodes of tonicclonic seizures. His condition further deteriorated when he fell unconscious and required ventilation support for two weeks. A CT scan of his brain revealed intraluminal filling defects in the superior sagittal sinus suggestive of thrombus with bilateral parietal subacute and acute hematoma. Following the scan, he was arranged for an emergency cerebral angiogram to confirm the diagnosis of SSST by a neurosurgeon. Further investigation with a blood test showed the protein $S$ antigen was low. Subsequently, he was treated conservatively with subcutaneous clexane and antiepileptic drugs.

He was discharged from the hospital after two months of admission with right hemiplegia and right facial palsy as well as motor aphasia. The rehabilitation process consisted of physiotherapy for body weaknesses, occupational therapy for basic daily living activities, and speech therapy. His cognitive function, physical and emotional status significantly improved two years post-stroke. He was able to speak, walk by himself and drive a car with steering modification.

To permit his return to work, the medical board of the Malaysian Armed Forces (MAF) needed to decide his new PULHEEMS status. The medical board consisted of three designated military doctors who would review reports or supporting documents from various relevant specialists such as a physician, neurosurgeon and psychiatrist. The findings from an assessment of physical examination by a physician showed his facial palsy was resolved, and limping gait but was able to stand without support. The right side of his body was highly affected with a contracture at the thumb and ring finger, increased tone, limited body movement and hyper reflexes. These findings resulted in grades of $\mathrm{P} 7$, $\mathrm{U} 7$ and L7. He was graded with $\mathrm{H} 1$ and E1E1 given no impairment in these qualities after the stroke event.

The assessment by the psychiatrist, including a normal result of MMSE, assured that his cognitive function is normal and no psychiatric disorders. Consequently, he was graded as M2 and S2. His final PULHEEMS assessment in table 2 showed his current capabilities only allowed him for employability in the base area in any part of Malaysia and fit to fly as a passenger in a normal passenger-carrying aircraft. He was permanently disqualified from military flying primarily due to his residual physical capabilities deficit and the $1 \%$ rule.

Table 2: The Grade of Degree Post Stroke Two Years

\begin{tabular}{llllllll}
\hline $\mathbf{P}$ & $\mathbf{U}$ & $\mathbf{L}$ & $\mathbf{H}$ & $\mathbf{E}$ & $\mathbf{E}$ & $\mathbf{M}$ & $\mathbf{S}$ \\
7 & 7 & 7 & 2 & 1 & 1 & 2 & 2 \\
\hline
\end{tabular}

Consequently, he was transferred to the military administrative office with a new job scope that related to his specialty of 15 years of aviation experience. He was given a task to manage an aviation-related building and supervise his subordinates. Because of his restrictions on the right side of the body, he was excused from military uniform, military salute and physical training tests such as heavy lifting, shooting exercise and operational exercise. He was provided with quarters near his office, and time off for continuing his weekly rehabilitation.

\section{DISCUSSION}

This case study illustrated implementation of international standards via a systematic approach to assist young stroke survivors to return to work. A synthesis of current knowledge would assist in providing good guidance on return to work.

Overall, the incidence of stroke in young adults has increased up to $40 \% .^{1}$ It was reported that the cumulative risks in 15 years for recurrent strokes was $19.1 \% .^{8}$ Specifically, SSST is a relatively uncommon disease and a rare cause of stroke. ${ }^{9}$ However, the presence of headache, hemiparesis, hemorrhages and focal epilepsy in a relatively young patient is a strong indicator of SSST. Coagulopathies such as protein $S$ deficiency is one of the underlying etiologies for SSST. Protein S is a vitamin K-dependent glycoprotein 
produced by the liver, vascular endothelium, monocytes, and megakaryocytes that helps in anticoagulation processes..$^{10}$ The deficiency of protein $S$ is a type of thrombophilia that leads to cerebral blood flow occlusion. Despite SSST being considered a rare occurrence, it had a favorable clinical outcome which can be measured by using the modified Rankin Scale (mRS) with a score of $\leq 2 .{ }^{9}$ This scale is used for measuring the degree of disability in the daily activities of people who have suffered a stroke or other causes of neurological disability. ${ }^{11}$ It describes 6 grades of disability after a stroke; grade 5 denotes severe disability or a bedridden patient, and grade 0 denotes no symptoms at all. Based on this case, the patient had a desirable outcome as shown in the previous study above. In this report, the PULHEEMS status of the patient was correctly reflected as described in the score of two in mRS whereby he had a slight disability with which he was still able to look after his affairs without assistance but unable to carry out all his previous duties.

Young stroke survivors have a high chance of achieving good outcomes with proper rehabilitation therapy, but sadly the return to work among them is not consistently high despite most ending up with relatively minor residual deficits such as cognitive function, speech and gait. The studies showed various ranges with an average of $44 \%$ return to work due to different aspects of studies on populations, types of strokes, study designs and methodologies. ${ }^{12}$ In this case, we see that the patient had improvement in overall physical and mental capacity two years post-stroke as stated in his latest PULHEEMS status. He was able to upgrade his qualities of $P, U$ and $L$ from degrees 0 to 7 and maintain the rest of the qualities with excellent degrees, respectively.

Return to work does not mean solely returning to a previous job or a similar job but it could be starting a new job, returning to an initial job with work accommodation for either part-time or full-time work. ${ }^{13}$ Despite a military pilot failing to achieve his previous normal PULHEEMS status due to unsuccessful regain of normal capabilities in physical capacity, upper limbs, locomotion and risk of a recurrent attack of stroke, an employer must not deny a patient's right to work with his remnant abilities. A stroke attack on a healthy military pilot with no significant risk factor should be considered as an unforeseen event that allows him to continue the service in the military in whatever capacity fits his current capabilities and mutual interests.
It was proven that those employers who are supportive and willing to modify the work environment contribute to increased success in return to work plans. ${ }^{14}$ Evidence in the systematic review showed workplace accommodation significantly promotes employability among persons with physical disabilities. ${ }^{15}$ This case report had highlighted the importance of proper aeromedical assessment and clear guidelines of return to work assessment by the organization, support from the employer and coworkers, the flexibility of work schedules and work organization as substantial key facilitators of stroke survivors reemployment.

The RMAF as an employer was able to adapt and provide necessity using the limit of organizational capacity. It was very impressive to see a big organization such as RMAF consider various aspects of a return-to-work assessment, including the patient's perspective. The patient's many years of experience and knowledge as a military pilot, his current disability of right-sided body weaknesses, remnant abilities and PULHEEMS status were all taken into consideration for accurate decision-making. All information was matched and suited to the most suitable new job scope. Therefore, work accommodation and welfare in respect to personal attributes, work characteristics and work environment are substantially needed in ensuring the successful return to work among stroke survivors especially those in working age.

\section{CONCLUSION}

The authors recommend that there is a need for reassessment up to two years using the objective PULHEEMS method for young pilots who failed aeromedical assessment due to stroke for returning to work as their experiences and knowledge are highly valuable.

\section{ACKNOWLEDGMENTS}

The authors would like to thank the Director Institute of Aviation Medicine, Royal Malaysian Air Force for permission to write this case report and Universiti Kebangsaan Malaysia for supporting this publication under grant GP-2020-K016553. We thank the pilot who consented to participate in the report. The opinions and assertions contained herein are the private opinions of the authors and are not to be construed as official or reflecting the views of the Institute of Aviation Medicine, Royal Malaysian Air Force. 


\section{REFERENCES}

1. Ekker MS, Boot EM, Singhal AB, Tan KS, Debette $S$, Tuladhar AM, et al. Epidemiology, aetiology, and management of ischaemic stroke in young adults. The Lancet Neurology. 2018;17(9):790-801. https:// doi.org/10.1016/S1474-4422(18)30233-3

2. World Stroke Organization.Global Stroke Fact Sheet. 2016. World Stroke Organization. Available from https://www.world-stroke.org/assets/downloads/ WSO_Global_Stroke_Fact_Sheet.pdf

3. Ekker MS, Verhoeven JI, Vaartjes I, Van Nieuwenhuizen KM, Klijn CJ, de Leeuw F-E. Stroke incidence in young adults according to age, subtype, sex, and time trends. Neurology. 2019;92(21):e2444-e54. https://doi.org/10.1212/ wnl.0000000000007533

4. Malaysian Armed Forces. Medical Administration and Technical Instruction Malaysia Armed Forces. Edition IV ed. Kuala Lumpur: Health Service Malaysian Armed Forces; 2016. Available from : https://www. mafhq.mil.my/index.php/en/\#Alvg5u3dD7U

5. Tunstall-Pedoe H. Acceptable cardiovascular risk in aircrew. Introduction. European heart journal. 1988; 9:9-11 Available from: https://doi.org/10.1093/ eurheartj/9.suppl_g.9

6. Evans S, Radcliffe S-A. The annual incapacitation rate of commercial pilots. Aviation, space, and environmental medicine. 2012;83(1):42-9. Available from :https://doi.org/10.3357/asem.3134.2012

7. Gray G, Bron D, Davenport ED, D'arcy J, Guettler N, Manen O, et al. Assessing Aeromedical Risk: A Three-Dimensional Risk Matrix Approach. Heart, 2019, 105 (Suppl 1): s9-s16. https://doi.org/10.1136/ heartjnl-2018-313052.

8. Aarnio K, Siegerink B, Pirinen J, Sinisalo J, Lehto M, Haapaniemi E, et al. Cardiovascular events after ischemic stroke in young adults: A prospective follow-up study. Neurology. 2016;86(20):1872-
9. Available from : https://doi.org/10.1212/ wnl.0000000000002689

9. Lee DJ, Ahmadpour A, Binyamin T, Dahlin BC, Shahlaie K, Waldau B. Management and outcome of spontaneous cerebral venous sinus thrombosis in a 5-year consecutive single-institution cohort. Journal of neurointerventional surgery. 2017;9(1):348. Available from : https://doi.org/10.1136/ neurintsurg-2015-012237

10. Ohashi I, Wada S, Yoshino F, Kuwashiro T, Matsumoto S, Hotta $\mathrm{T}$, et al. Ischemic Stroke with Protein $S$ Deficiency Treated by Apixaban. Journal of Stroke and Cerebrovascular Diseases. 2020;29(4):104608. Available from: https://doi. org/10.1016/j.jstrokecerebrovasdis.2019.104608

11. Saver JL, Filip B, Hamilton S, Yanes A, Craig S, Cho $\mathrm{M}$, et al. Improving the reliability of stroke disability grading in clinical trials and clinical practice: the Rankin Focused Assessment (RFA). Stroke. 2010;41(5):992-5. Available fro : https://doi. org/10.1161/strokeaha.109.571364

12. Bultmann U, Siegrist J. Return to Work After Stroke. Handbook of Disability, Work and Health. Spinger. 2020:1-16.

13. Edwards JD, Kapoor A, Linkewich E, Swartz RH. Return to work after young stroke: A systematic review. International journal of stroke: official journal of the International Stroke Society. 2018;13(3):243-56. Available from : https://doi. org/10.1177/1747493017743059

14. Kwan HC, Schultz IZ. Work accommodations: a social perspective. Handbook of Return to Work: Springer; 2016. p. 271-88.

15. Nevala N, Pehkonen I, Koskela I, Ruusuvuori J, Anttila $\mathrm{H}$. Workplace accommodation among persons with disabilities: A systematic review of its effectiveness and barriers or facilitators. Journal of occupational rehabilitation. 2015;25(2):432-48. Available from : https://doi.org/10.1007/s10926-014-9548-z. 